\title{
Mass Customization Methodology for Footwear Design
}

\author{
Yifan Zhang ${ }^{1}$, Ameersing Luximon ${ }^{1}$, Xiao $\mathrm{Ma}^{1}$, Xiaoling Guo ${ }^{2}$, and Ming Zhang ${ }^{3}$ \\ ${ }^{1}$ Institute of Textiles and Clothing, The Hong Kong Polytechnic University, \\ Hung Hom, Kowloon, Hong Kong \\ ${ }^{2}$ Zhongshan Boai Hospital, Guangdong, China \\ ${ }^{3}$ Department of Health Technology and Informatics, The Hong Kong Polytechnic \\ University, Hung Hom, Kowloon, Hong Kong \\ tcshyamapolyu.edu.hk
}

\begin{abstract}
Nowadys consumers are sophisticated and want better quality personalized products at lower prices. In order to satisfy consumers, footwear companies have to predict consumers' trends and produce huge varieties of designs using mass production technologies. This results in wastage and high inventory cost. Recently mass customization methodologies have been proposed. Mass customization enables the design and production of an almost custom made product at almost mass production costs. This can be achieved by reducing the wastage and inventory cost. The products are designed specifically for the consumer, eventually improving consumer satisfaction and the companies' market share. Many researchers have discussed the framework of mass customization; however, there is limited study on the system details, especially for footwear design. The main purpose of this research is to propose a methodology for the mass customization of footwear - both style and fit customization.
\end{abstract}

Keywords: Footwear design, Mass customization, Custom footwear, Style customization, Fit customization, Computer-Aided design (CAD) technology.

\section{Introduction}

The traditional methods of production, used by manufacturing companies, focus on mass production. Mass production technique tends to produce large quantities of products with minor variations. Nowadays, the combination of globalization and digitalization has tremendous economic impact and has radically transforms the environments in which companies operate. The internationalization and digitalization of the markets offer companies the possibility to diversify their supply, production and distribution networks. Facing a plethoric supply, consumers have become more demanding and selective. Product with variation and customization is a trend in current market-oriented manufacturing environment. Companies try to respond as precisely as possible to consumers' needs with highly focused products, each one aiming at a specific and highly differentiated consumer class, or each being personalized for a single consumer [1]. Mass customization relates to the ability to provide customized products or services through flexible 
processes in high volumes and at reasonably low costs [2]. Selladurai [3] studied the methods to achieve mass customization. He explained why the term is not an oxymoron but describe a true situation. He looked at the advantages and disadvantages, and discussed how it may be effectively used in production and operations management. Similarly, Aigbedo [4] proposed a framework for evaluating the levels of mass customization that enables the manufacturer to meet consumers' requirements in a cost effective manner.

The shoe industry is no exception. It is a very competitive industry with many companies and educated consumers. Consumers' preferences and perception of shoes strongly influence their acceptance. Today's consumers, especially the young, are more sophisticated. They demand shoes to satisfy their needs at reasonable prices. At the same time, they wish to personalize the style and fit of their shoes. In order to capture the footwear market, companies need to manufacture customized shoes to satisfy consumer's needs on style, fit and comfort. In order to enable footwear customization, the most important aspect is to design a customized, or better fitting shoe-last [5-7]. A shoe-last, 3D mold used for making footwear, has a relatively complex shape without any straight lines and is normally made of high density polyethylene [8]. To realize footwear fit customization, it is necessary to consider the wide variations in dimension, weight, shape, surface area, volume and composition. For mass production, the footwear fit is influenced by sizing and grading methods [916]. For footwear, there is a choice to customize the fit or the style. The aim of this study is to create a methodology to customize shoes for fit as well as style depending on consumer's requirements. Previous studies [17-19] have discussed the framework of footwear mass customization, however very few of them have discussed the details in terms of Computer-Aided Design (CAD) technologies. In this study, the processes of generating designs and design modification of shoe-lasts are also discussed. Since 3D foot scanned data are used, the system enables design customization, as well as fit customization.

\section{Method}

The framework of the proposed study is shown in Fig. 1. The frameworks indicate that mass produced shoes; fit customized shoes; style customized shoes; and style and fit customized shoes were produced. For mass produced shoes, the consumer's feet anthropometric measures are required to extract the size information. In case the consumer has digital foot data acquired from a foot scanner, the size information were extracted from the digital foot. Based on the sizing information, the shoe-last can be sized and graded, and shoes are produced according to mass production techniques.

\subsection{Customization of Mass Produced Shoes via Sizing and Grading}

Each country has its own guidelines for shoe-last sizing and grading; however, methods for shoe-last design are limited. Two widely used shoe-last design guidelines 


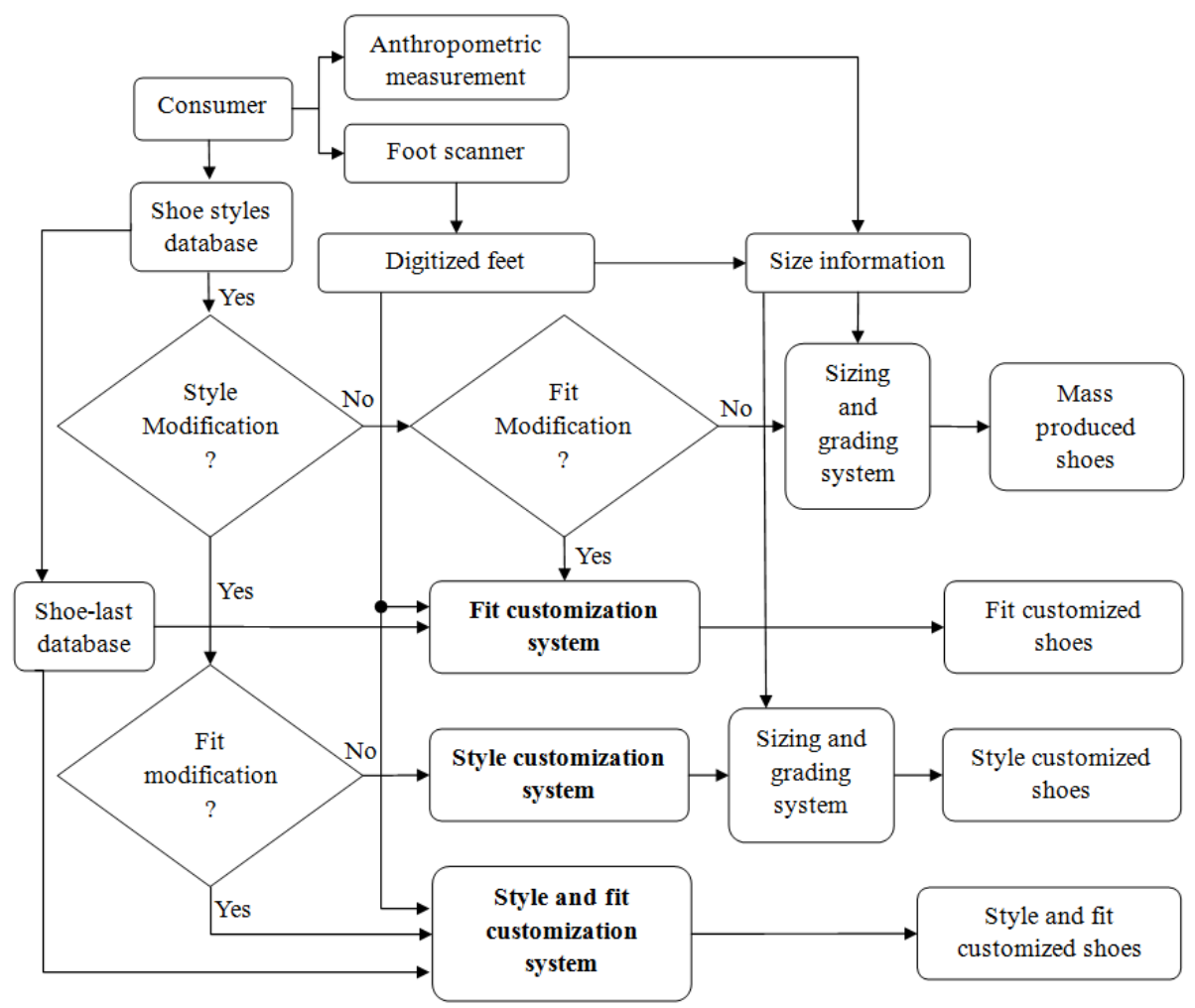

Fig. 1. Framework of mass customized shoe design system
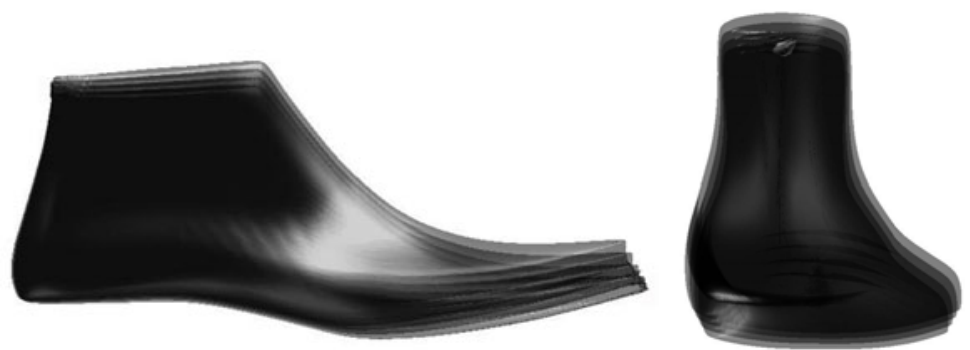
(a) Side view
(b) Front view

Fig. 2. Sizing and grading system 
include the AKA64-WMS American system [20, 21] and the Chinese system National Footwear Research Institute, Chinese Shoe Size and Last Design, China Light Industry Press, Bei Jing (1984) (in Chinese).[22].The AKA64 system, developed in 1964, was based on anthropometric study of children and is now used for sizing children as well as adults [21]. Fig. 2 shows the shoe-last sizing and grading according to the American system. Currently sizing and grading is based on foot length and foot girth. If a better sizing and grading method were developed, even using mass production technologies footwear fit and comfort can be improved. In addition, by using half sizes, the tolerance was improved.

\subsection{Style Customization}

In addition to mass customized footwear, consumers can decide on style customization. The style customization can accomplish by modification of the upper or the modification of the shoe-last (Fig. 3). When modifying the shoe-upper, the consumers can decide to change the style lines to create new designs (Fig. 4a and Fig. 4b). This was done by modifying the style curves that were represented in terms of splines or NURBS curves. The style was modified by removing or adding accessories, such as removal of buckles (Fig. 4c). In addition, the style and fashion were modified by changing material (Fig. 4d and Fig. 4e) and color (fig. 4f). For the shoe-last style modification, the toe design (Fig. 5 and Fig. 6a), toe spring and heel height (Fig. 6b) were modified. It should be noted that modification of the toe design, toe spring and heel height will also influence the fit to some extent. Shoe-last style modification is included in shoe style modification, because normal sizing and grading is used after the shoe style modifications (Fig 1).

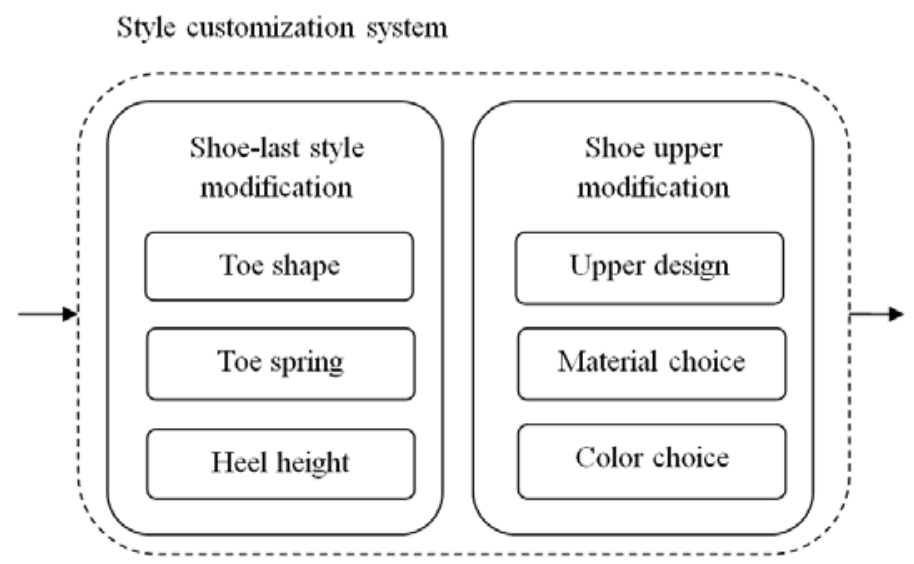

Fig. 3. Framework of shoe style customization system 


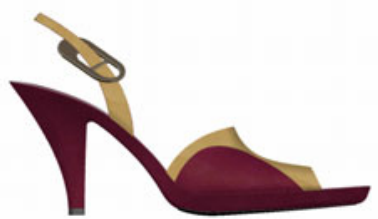

(a)

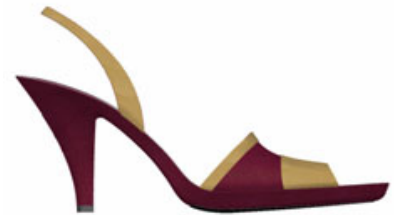

(d)

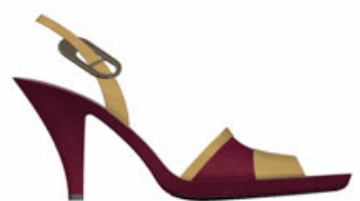

(b)

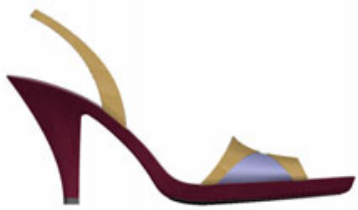

(e)

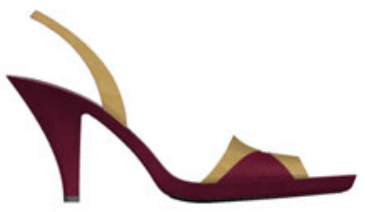

(c)

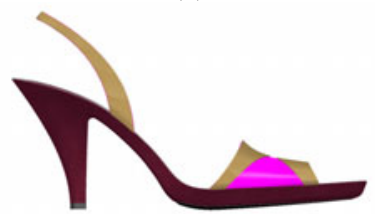

(f)

Fig. 4. Shoe style modification

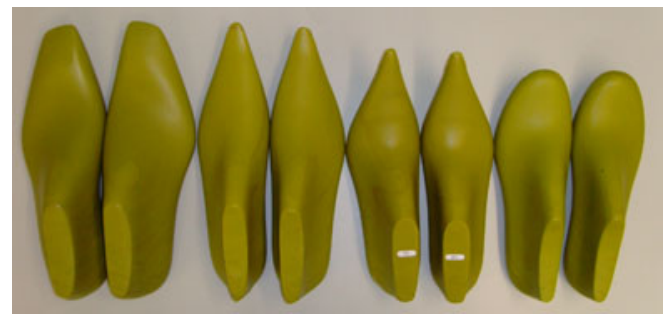

Fig. 5. Shoe-lasts
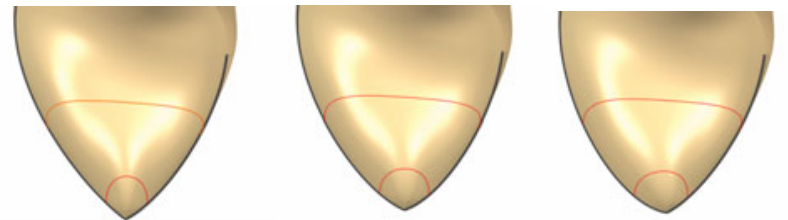

(a) Modification of toe shape
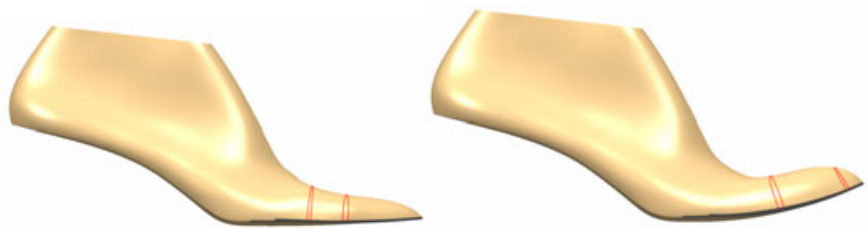

(b) Modification of toe spring

Fig. 6. Shoe-last style modification 


\subsection{Fit Customization}

To some extent, the fit were customized by modification of the shoe-last style. However, fit customization will be done mostly by modification of the shoe-last according to consumer's feet data (Fig. 7). From the digital foot data, foot parameters are extracted. The number of parameters will influence the degree of fit customization. For example, the parameters can be foot length, foot flare, foot width, and foot height. Similar to foot parameters, the matching shoe-last parameters are extracted. The shoe-last is then modified based on the shoe parameters and given tolerances to create customized shoe-last (Fig. 8). The customized shoe-lasts were used for making customized shoes.

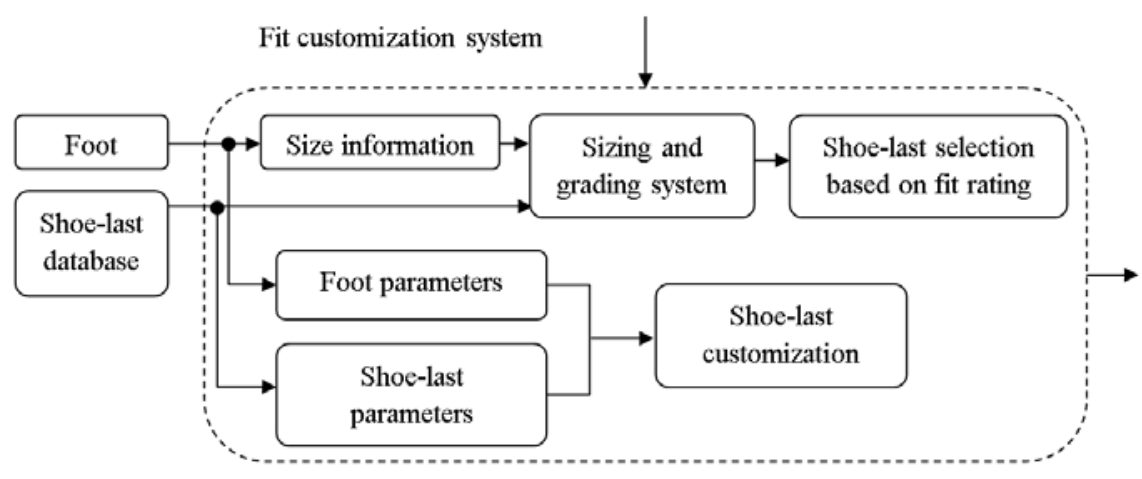

Fig. 7. Framework of shoe fit customization system

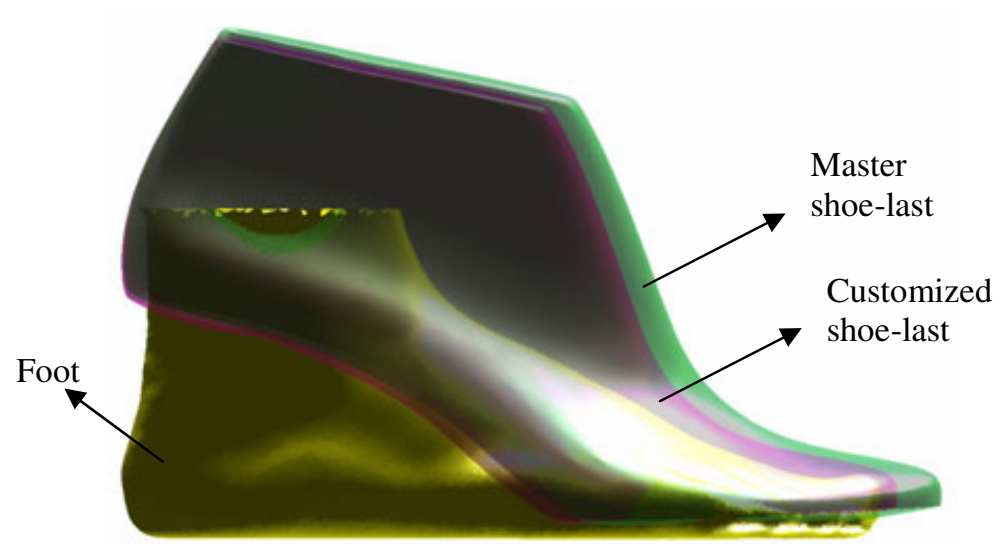

Fig. 8. Custom made shoe-last 


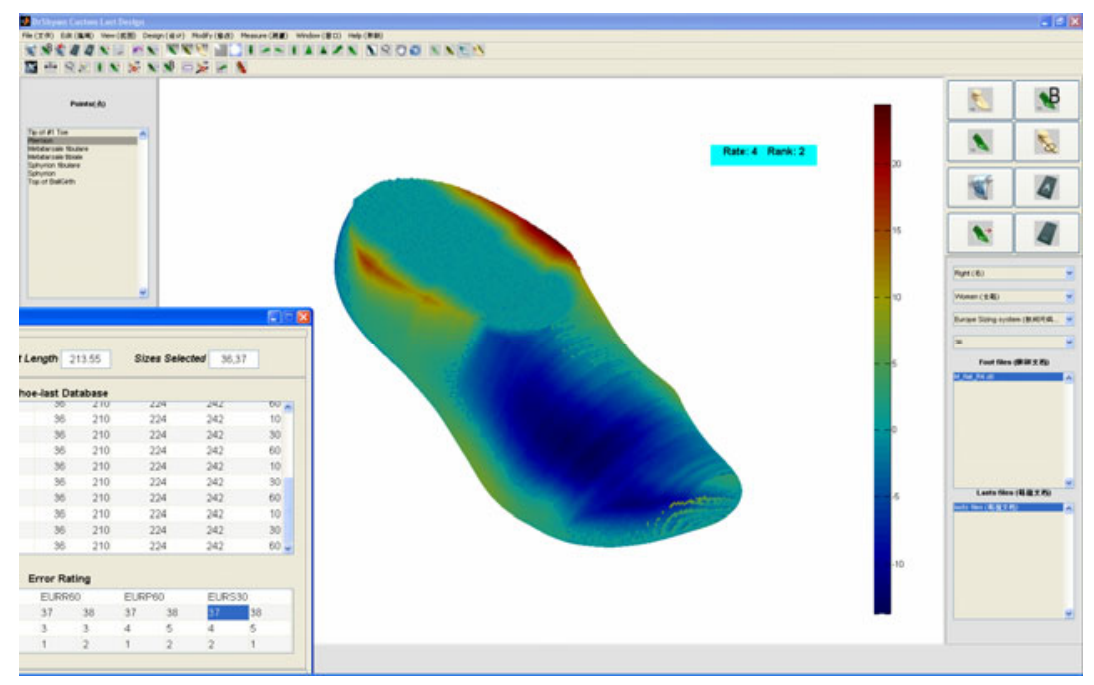

Fig. 9. Shoe-last selection using fit rating

Also, the consumers can have a choice to decide on shoe-last based on the different quality of fit. This was achieved by selecting different shoes based on the consumer's preference. Based on the shoes the matching shoe-last were extracted. The selected shoe-lasts were graded and sized based on the size information of the consumer. The modified shoe-lasts were compared with the feet to create fit rating [6] and ranking of the shoe-lasts (Fig. 9). Based on the rating and ranking, consumers can select the shoes.

\subsection{Fit and Style Customization}

Depending upon the costs, most customers will prefer to have both fit and style customization (Fig. 1). With style and fit customization, the customer has the freedom to modify the style of the shoe-last and the shoe. In addition, to modification of the shoe-last and the shoe style, the shoe-last were modified to account for variation in the foot.

\section{Discussion and Conclusion}

Mass customization is a solution to address the new market realities while still enabling manufacturers to capture the efficiency advantages of mass production. In this study, footwear customization methodology has been discussed; both style and fit are customized. The proposed methodology considers the entire different scenario for footwear customization. Previous studies on different level of fit customization $[5,6]$ can be incorporated in the proposed system. This system is advantageous to the consumers, footwear industries and the society. Consumers are able to design their shoes according to their style and fit requirements, while footwear industries are able 
to increase market share, reduce waste and inventory cost. In addition, mass customization benefits to the society as it creates less pollution.

Acknowledgment. This work was supported by The Hong Kong Polytechnic University PhD studentship.

\section{References}

1. Labarthe, O., Espinasse, B., Ferrarini, A., Montreuil, B.: Toward a Methodological Framework for Agent-Based Modelling and Simulation of Supply Chains in a Mass Customization Context. Simulation Modelling Practice and Theory 15(2), 113-136 (2007)

2. Silveira, G.D., Borenstein, D., Fogliatto, F.S.: Mass Customization: Literature Review and Research Directions. International Journal of Production Economics 72, 1-13 (2001)

3. Selladurai, R.S.: Mass Customization in Operations Management: Oxymoron or Reality? Omega 32(4), 295-300 (2004)

4. Aigbedo, H.: An Assessment of the Effect of Mass Customization on Suppliers' Inventory Levels in a JIT Supply Chain. European Journal of Operational Research 181(2), 704-715 (2007)

5. Luximon, A., Goonetilleke, R.S.: A 3-D Methodology to Quantify Footwear Fit. In: Tseng, M.M., Piller, F. (eds.) The Customer Centric Enterprise- Advances in Customization and Personalization, ch. 28, pp. 491-499. Springer, Heidelberg (2003)

6. Luximon, A., Goonetilleke, R.S.: A Fit Metric for Footwear Customization. In: Proceedings of World Congress on Mass Customization and Personalization, Hong Kong (2001)

7. Luximon, A., Luximon, Y.: Shoe-last Design Innovation for Better Shoe Fitting. Computers in Industry 60(8), 621-628 (2009)

8. Cheskin, M.P.: The Complete Handbook of Athletic Footwear. Fairchild Publications, New York (1987)

9. Ball, R., Shu, C., Xi, P.C., Rioux, M., Luximon, Y., Molenbroek, J.: A Comparison Between Chinese and Caucasian Head Shapes. Applied Ergonomics 41(6), 832-839 (2010)

10. Chen, W., Zhuang, Z., Benson, S., Du, L., Yu, D., Landsittel, D., Wang, L., Viscusi, D., Shaffer, R.E.: New respirator fit test panels representing the current Chinese civilian workers. Annals of Occupational Hygiene 53(3), 297-305 (2009)

11. Kouchi, M., Mochimaru, M.: Analysis of 3D Face Forms for Proper Sizing and CAD of Spectacle Frames. Ergonomics 47(14), 1499-1516 (2004)

12. Jussi, R.: Evaluation of an Augmented Reality Audio Headset and Mixer. Master's Thesis, Helsinki University of Technology (2009)

13. Robinette, K.M., Annis, J.F.: A Nine-Size System for Chemical Defense Gloves. Technical rept. Anthropology Research Project Inc. Yellow Springs Oh (1986)

14. Luximon, A., Goonetilleke, R.S.: Critical Dimensions for Footwear Fitting. In: Proceedings of IEA 2003 Conference, CD-ROM (2003)

15. Zheng, R., Yu, W., Fan, J.T.: Development of a New Chinese Bra Sizing System Based on Breast Anthropometric Measurements. International Journal of Industrial Ergonomics 37, 697-705 (2007)

16. Maria, L.M., Philip, N.A., Nickolas, S.S.: A New Methodology for the Development of Sizing Systems for the Mass Customization of Garments. International Journal of Clothing Science and Technology 22(1), 49-68 (2010) 
17. Sheffer, A., de Sturler, E.: Parameterization of Faceted Surfaces for Meshing Using Angle Based Flattening. Engineering with Computers 17(3), 326-337 (2001)

18. Lee, Y., Kim, H.-S., Lee, S.: Mesh Parameterization with a Virtual Boundary. Computers and Graphics 26(5), 677-686 (2002)

19. Luximon, A., Luximon, Y.: Creation of Design Variations Using CAD. In: 86th Textile Institute World Conference Proceedings, Hong Kong, pp. 1465-1471 (2008)

20. Adrian, K.C.: American Last Making: Procedures, Scale Comparisons, Sizing and Grading Information. In: Basic Shell Layout Bottom Equipment Standards. Shoe trades publishing Co., Arlington (1991)

21. Pivecka, J., Laure, S.: The Shoe Last: Practical Handbook for shoe Designers. Pivecka Foundation, Slavicin (1995)

22. National Footwear Research Institute, Chinese Shoe Size and Last Design. China Light Industry Press, Beijing (1984) (in Chinese) 